\title{
AVALIAÇÃO DA BIODEGRADAÇÃO DO INSETICIDA IMIDACLOPRIDO EM REATOR DE BANCADA
}

\section{EVALUATION OF IMODACLOPRIDO INSECTICIDE BIODEGRADATION IN BANK REACTOR}

Roberta Daniela da Silva Santos

Mestre em Engenharia de Recursos Hídricos e Sanitária. Doutoranda em Irrigação e Drenagem, Universidade Estadual Paulista "Júlio de Mesquita Filho". (roberta dani30@hotmail.com)

Paula Tereza de Souza e Silva

Doutora em Química, Universidade Federal de Pernambuco. Embrapa Semiárido. (paula.silva@embrapa.br)

Carlos Alberto Tuão Gava

Doutor em Produção Vegetal, Universidade Estadual do Norte Fluminense Darcy Ribeiro. Embrapa Semiárido. (carlos.gava@embrapa.br)

Veruschka Escarião Dessoles Monteiro

Doutora em Engenharia Civil, Universidade Federal de Pernambuco. Universidade Federal de Campina Grande / Departamento de Engenharia Civil . (veruschkamonteiro@hotmail.com)

\section{Márcio Camargo de Melo}

Doutor em Ciências e Engenharia de Materiais, Universidade Federal de Campinha Grande. Universidade Federal de Campina Grande / Unidade Acadêmica de Engenharia Agrícola. (melomc90@gmail.com)

\section{Resumo}

Na Região do Vale do São Francisco, no estado de Pernambuco, o manejo da uva requer a utilização de inseticidas para combate às pragas, dentre eles, destaca-se o imidacloprido. A utilização de inseticidas acarreta na geração de efluentes contaminados, provenientes das sobras da pulverização e das águas de lavagens dos equipamentos destinados a essa atividade, os quais, se não forem tratados corretamente, podem contaminar os recursos naturais. O objetivo deste trabalho foi avaliar a biodegradação do inseticida imidacloprido, empregando reator de bancada, combinando aeração e esterco caprino. Para avaliar as melhores condições de biodegradação, utilizou-se um planejamento fatorial $2^{2}$ verificando a influência da razão efluente / biomassa (95/5 e 80/20) e do tempo de detenção (15 e 23 dias). As variáveis avaliadas foram nitrogênio total, oxigênio dissolvido, temperatura, carbono orgânico total, contagem de microrganismos e análise do imidacloprido no efluente e no esterco caprino. Verificou-se que os microrganismos presentes no esterco caprino foram promissores na biodegradação do imidacloprido.

Palavras-chave: Biodegradação, inseticida, efluente.

\section{Abstract}

In the São Francisco Valley Region, in the state of Pernambuco, grape management requires the use of insecticides to combat pests, among which, imidacloprid stands out. The use of insecticides entails the generation of contaminated effluents from the spray surpluses and washes of the equipment destined to this activity. These effluents if not treated properly can contaminate natural resources. The objective of this research was to evaluate the biodegradation of the imidacloprid insecticide, using a bench reactor combining aeration and goat manure. To evaluate the best biodegradation conditions, a factorial design $2^{2}$ was used to verify the influence of the effluent / biomass ratio (95/5 and 80/20) and the time of detention (15 and 23 days). The variables evaluated were total nitrogen, dissolved oxygen, temperature, total organic carbon, counting of microorganisms and analysis of imidacloprid in effluent and goat manure. The resultes shows that the microorganisms present in goat manure were promising in the biodegradation of the imidacloprid.

Keywords: Biodegradation, inseticides, effluent. 


\section{INTRODUÇÃO}

A agricultura passou por mudanças significativas na década de 50 , durante a revolução verde. Tais mudanças contemplaram, principalmente, a inserção de novas tecnologias e o uso extensivo de agrotóxicos no controle de pragas e doenças. Esse cenário, marcado, sobretudo, pela monocultura (cana de açúcar, soja, milho, fruticultura etc.) e pela produtividade em larga escala, ocasionou uma série de impactos no meio ambiente e na saúde humana (RIBAS; MATSUMURA, 2009).

No mundo, são consumidas, anualmente, cerca de 2,5 milhões de toneladas de agrotóxicos, e no Brasil esse consumo supera 300 mil toneladas. O Vale do São Francisco é responsável por uma parcela significativa do consumo nacional de agrotóxicos, pois essa região domina as exportações brasileiras, uma vez que a produção de manga e uva abastece os mercados mais exigentes do mundo (ABRASCO, 2012).

A utilização de agrotóxicos no controle de pragas e doenças acarreta na geração de alguns passivos ambientais, como, por exemplo, os efluentes contaminados, provenientes das sobras da pulverização e águas de lavagens dos equipamentos destinados a essa atividade. Esses efluentes se não forem tratados corretamente podem contaminar os recursos naturais.

A literatura é vasta no que diz respeito à contaminação de águas superficiais e subterrâneas por agrotóxicos. Autores como Reilly et al. (2012) constataram a presença de pelo menos um fungicida em $75 \%$ das águas superficiais e $58 \%$ dos poços amostrados em áreas agrícolas dos Estados Unidos.

Herrero-Hernandéz et al. (2013) encontraram resíduos de agrotóxicos em $64 \%$ das águas subterrâneas e $62 \%$ das águas superficiais analisadas, sendo o somatório de todos os compostos encontrados superior ao limite previsto na legislação da União Europeia, para corpos hídricos destinados ao abastecimento.

Em âmbito nacional, a situação não é diferente. Várias pesquisas (BORTOLUZZI et al., 2006; FERNANDES NETO; SARCINELLI, 2009; MARCHESAN et al., 2010; SILVA et al., 2011; MOREIRA et al., 2012; CARNEIRO, 2015; FERREIRA et al., 2016; SOARES; FARIA; ROSA, 2017) constataram a presença de agrotóxicos em águas superficiais, subterrâneas e, de maneira alarmante, em águas pluviais.

O Vale do São Francisco, consagrado mundialmente como um dos principais polos viticultor do Brasil, utiliza uma diversidade de inseticidas para controlar pragas e doenças. Dentre eles, destaca-se o imidacloprido, que é amplamente utilizado no combate a pragas sugadoras, como, por exemplo, tripes (Selenothrips rubrocinctus e Frankliniella $s p$.) e cochonilha (Parthenolecanium persicae). Segundo a ANVISA (2007), o Imidacloprido é um inseticida sistêmico de nome químico 1-(6-chloro-3pyridylmethyl)- $\mathrm{N}$-nitroimidazolidin-2-ylideneamine, cuja fórmula bruta é $\mathrm{C}_{9} \mathrm{H}_{10} \mathrm{CIN}_{5} \mathrm{O}_{2}$, pertencente ao grupo químico neonicotinóide. Esse produto é medianamente tóxico, apresenta solubilidade relativamente elevada e estabilidade na água, criando significativas preocupações ambientais (SEGURA et al., 2008; TISLER et al., 2009; PATIL, PATIL; GOGATE; PANDIT et al., 2014).

Os métodos de tratamento amplamente utilizados para degradar efluentes contaminados com agrotóxicos são incineração, ozonização, degradação fotocatalítica, processos oxidativos avançados, adsorção, fitorremediação e biodegradação (CARDEAL; SOUZA; AMORIM et al., 2011; HATTAB; GHALY, 2012). Esta última, a biodegradação, segundo Diez (2010), é bastante eficaz na remoção dessas substâncias do meio ambiente. Gogate e Pandit (2004) salientam em seus estudos que o tratamento biológico de efluentes contaminados com agrotóxicos é uma alternativa econômica e ambientalmente sustentável.

Conforme Delgado-Moreno, Nogales e Romero (2017), os sistemas biológicos também conhecidos por biobeds, nos quais predomina o processo de biodegradação, implementados com resíduos orgânicos da agroindústria do azeite, foram capazes de remover os agrotóxicos dimetoato, imidacloprido, tebuconazol, diuron e oxifluorfen.

Em se tratando de biodegradação do inseticida imidacloprido, Phugare et al. (2013) avaliaram a degradação desse agrotóxico por uma bactéria isolada Klebsiella pneumoniae estirpe $\mathrm{BCH} 1$. A bactéria foi capaz de degradar $78 \%$ da concentração inicial, em um período de sete dias a uma temperatura de $30^{\circ} \mathrm{C}$.

Outro estudo nessa mesma perspectiva foi o de He et al. (2014), em que os autores estudaram a biodegradação de imidacloprido através de 
microrganismos modificados de Trichoderma. A comunidade modificada conseguiu atingir $95 \%$ de degradação do imidacloprido.

Pesquisas realizadas por Mohammed e Badawy (2017), Delgado-Moreno, Nogales e Romero (2017), Sharma, Singh e Gupta (2014) e Herner, Kucic e Zelic (2017) afirmam que o processo de biodegradação é altamente eficiente na remoção do imidacloprido em efluentes contaminados.

Dessa forma, o objetivo desse trabalho é avaliar a capacidade de um sistema biológico, que combina aeração e esterco caprino, de degradar o inseticida imidacloprido.

\section{METODOLOGIA}

O experimento foi conduzido em escala laboratorial, utilizando efluente sintético com concentração equivalente a $2,5 \mathrm{mg} \mathrm{L}^{-1}$, preparado a partir de um produto comercial que contém 200 $\mathrm{g} \mathrm{L}^{-1}(20 \% \mathrm{~m} / \mathrm{v})$ de Imidacloprido (princípio ativo P.A.) e $900 \mathrm{~g} \mathrm{~L}^{-1}(90 \% \mathrm{~m} / \mathrm{v})$ de ingredientes inertes.

O delineamento experimental empregado foi um planejamento fatorial $2 \times 2$ com três repetições (Figura 1). As variáveis foram tempo de detenção e razão efluente/biomassa, cada uma com dois níveis (Tabela 1), produzindo quatro tratamentos. O mesmo delineamento foi usado para as amostras controle, compostas de água e esterco. O objetivo desse delineamento foi estudar a influência do tempo de detenção e da razão efluente/biomassa na biodegradação do imidacloprido. A escolha dos tempos de detenção e razões biomassa/efluente foi baseada nos sistemas de tratamento de efluentes adotados pelas fazendas produtoras de uva, localizadas no Vale do São Francisco.

Figura 1: Esquema da disposição dos reatores no experimento.

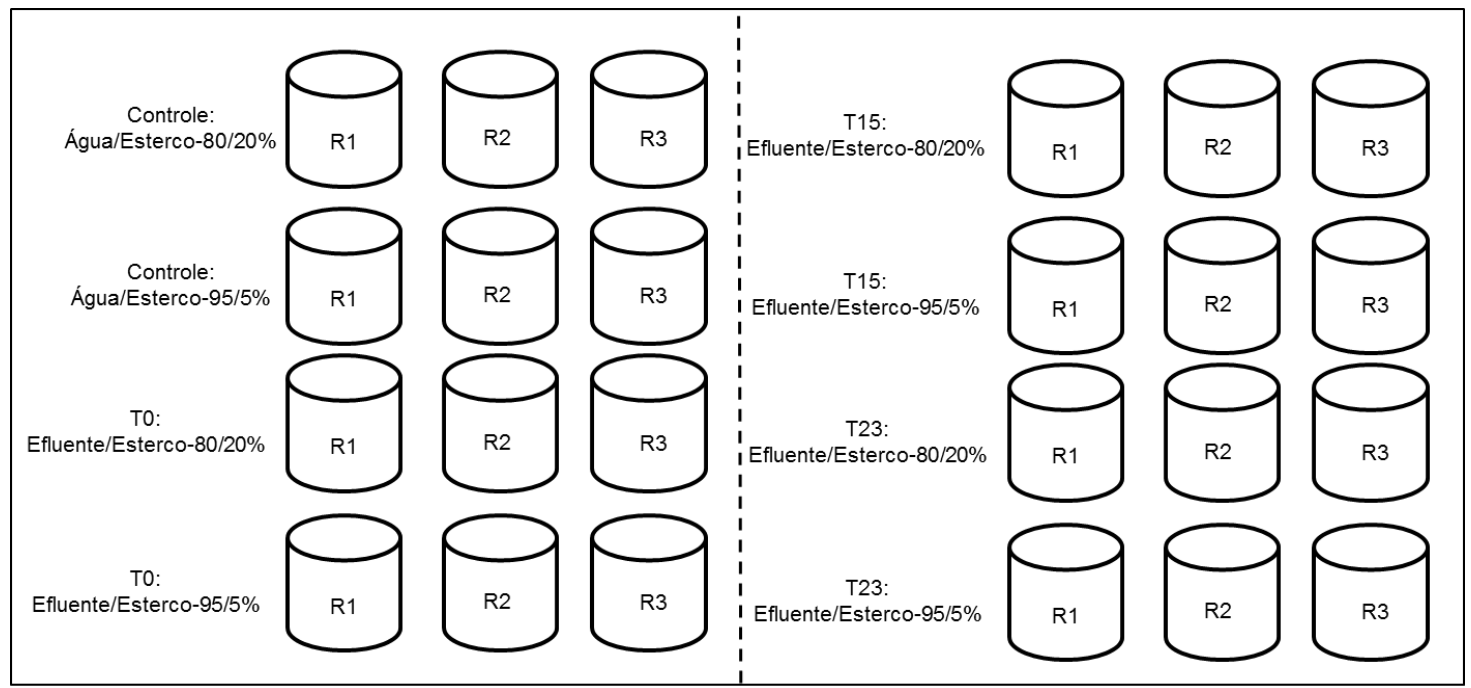

Fonte: Autores.

Tabela 1: Níveis das variáveis do planejamento fatorial $2 \times 2$.

\begin{tabular}{ccc}
\hline Ensaio & Tempo de Detenção (Dias) & Razão Efluente/biomassa (\%) \\
\hline 1 & $-(15)$ & $-(95 / 5)$ \\
2 & $+(23)$ & $-(95 / 5)$ \\
3 & $-(15)$ & $+(80 / 20)$ \\
4 & $+(23)$ & $+(80 / 20)$ \\
\hline
\end{tabular}

Fonte: Autores. 
Para simular os reatores, foram utilizados vasos plásticos com capacidade para 3 litros, preenchidos com 1,2 litros do efluente sintético e esterco caprino na respectiva proporção (Figura 2). O esterco foi previamente triturado, para uniformizar a amostra e aumentar a superfície de contato com 0 efluente. Esse sistema permaneceu sob aeração constante durante todo o experimento. A oxigenação do sistema se deu através de bombas de aeração para aquário.

Figura 2: Montagem do experimento.

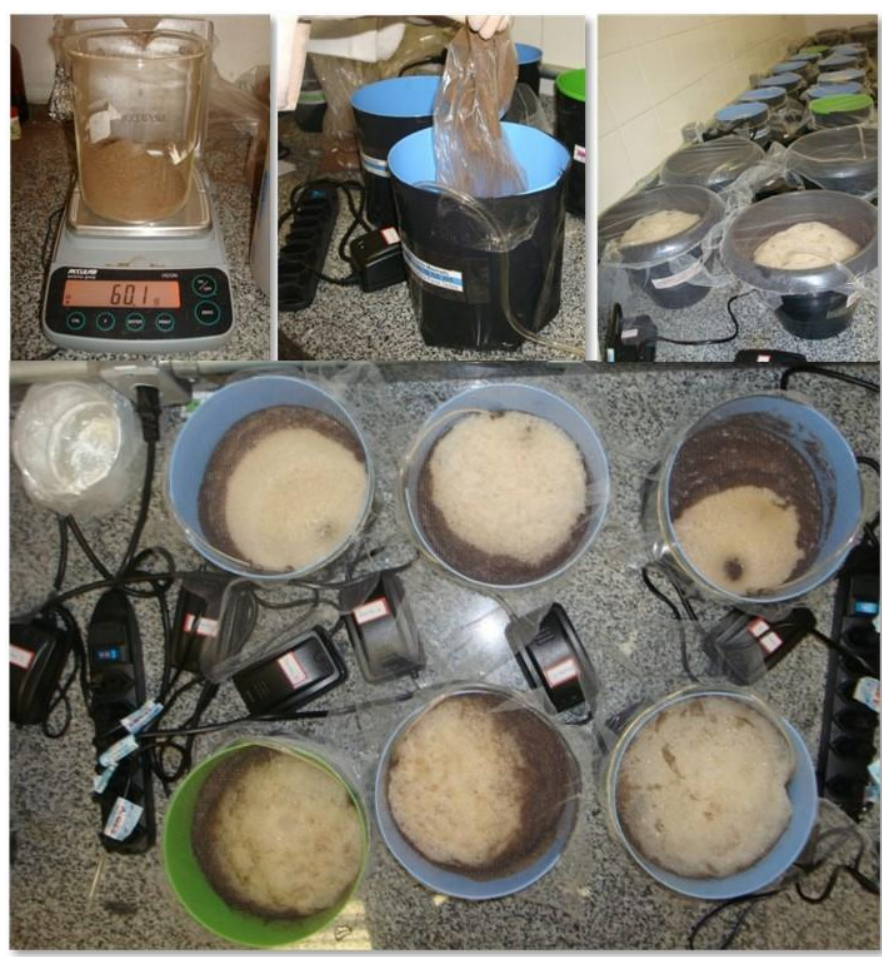

Fonte: Autores.

As coletas das amostras de efluente $\mathrm{e}$ esterco nos reatores ocorreram no dia em que 0 experimento foi montado, após 15 e 23 dias de tratamento. Em cada coleta, foi retirado todo 0 conteúdo dos reatores; em seguida, as amostras foram encaminhadas para as análises laboratoriais.

\subsection{Análises laboratoriais}

\subsubsection{Físico-química}

No efluente, as variáveis analisadas foram: Temperatura, Oxigênio Dissolvido, Nitrogênio Total e Carbono Orgânico Total, segundo metodologia do Standard Methods Analysis Water and Wastewater (APHA, 2012). Essas análises efetuaram-se no Laboratório Agroambiental da Embrapa Semiárido.

\subsubsection{Microbiológica}

As análises microbiológicas no efluente foram realizadas apenas para quantificar os microrganismos, segundo a mesma metodologia (APHA, 2012), porém, com adaptações.

Nas análises microbiológicas, utilizaram-se três meios de cultura, com o objetivo de estimular o crescimento de microrganismos degradadores, pois a única fonte de nutrientes nesse meio é o próprio agrotóxico, a saber: NA (ágar nutriente); $\mathrm{NA}+\mathrm{P}$.A. [ágar nutriente com adição do produto comercial contendo 0 princípio ativo imidacloprido, na mesma concentração do efluente $\left(2,5 \mathrm{mg} \mathrm{L}^{-1}\right)$ ]; e Pobre+P.A. [Yeast extract powder com ágar nutriente e $1 \%\left(2 \mathrm{~g} \mathrm{~L}^{-1}\right)$ do teor de princípio ativo de imidacloprido existente na formulação do produto comercial]. Na Tabela 2, constam as finalidades dos respectivos meios de cultura. 
Tabela 2: Meios de cultura e seus objetivos. Objetivo

Quantificar os microrganismos totais

NA+P.A.

Pobre+P.A.
Estimular o crescimento de microrganismos degradadores, pois a única fonte de nutrientes nesse meio é o próprio agrotóxico

Fonte: Autores.

$\mathrm{Na}$ capela de fluxo laminar, procedeu-se a diluição em série das amostras em água destilada esterilizada, com fator de diluição de 1:10 até $10^{-5}$. Foram retiradas alíquotas de $0,1 \mathrm{~mL}$ das diluições $10^{-4}$ e $10^{-5}$ em triplicata, as quais foram distribuídas e espalhadas com auxílio de alça de Drigalski em placas de Petri, contendo os meios de cultura descritos. As placas foram, então, incubadas a $28{ }^{\circ} \mathrm{C}$ durante 7 dias em câmera de crescimento (BOD). Decorrido os sete dias, procedeu-se a contagem do número de colônias.

Todo esse procedimento foi realizado com todas as amostras de efluente nos diferentes tempos de detenção. Efetuaram-se as análises no Laboratório de Controle Biológico da Embrapa Semiárido.

\subsubsection{Resíduos de agrotóxico}

As análises dos resíduos de agrotóxico foram realizadas no Laboratório de Bioquímica da Universidade Federal do Vale do São Francisco UNIVASF. Procedeu-se estudo de recuperação do imidacloprido, tanto no esterco quanto no efluente, no qual as concentrações de inseticida e - percentual de recuperação variaram, respectivamente, entre $3,4-4,8 \mathrm{mg} \mathrm{L}^{-1}$ e $82-$ $108 \%$ para o esterco, e de $3,4-3,9 \mathrm{mg} \mathrm{L}^{-1} \mathrm{e} 82,8$ - 95,5\% para o efluente. A metodologia utilizada permitiu atingir o LD de $11 \mu \mathrm{g} \mathrm{L-1}$, e os percentuais de recuperação se encaixam dentro da faixa aceitável que, segundo Ribani (2004), é de 70 a $120 \%$.

Fizeram-se análises de Resíduos de Agrotóxicos no efluente. As amostras foram inicialmente filtradas em membranas de 0,45 $\mu \mathrm{m}$ para remoção de partículas em suspensão e acidificadas com ácido sulfúrico P.A. Foram transferidos $10 \mathrm{~mL}$ da amostra para tubo falcon de $15 \mathrm{~mL}$, adicionou-se $2 \mathrm{~g}$ de $\mathrm{NaCl}$, seguido de agitação em Vortex por $1 \mathrm{~min}$. Em seguida, adicionou-se $3 \mathrm{~mL}$ de diclorometano $\left(\mathrm{CH}_{2} \mathrm{Cl}_{2}\right)$ da marca VETEC Química Fina, seguido de agitação em Vortex por $3 \mathrm{~min}$. Após a extração, as amostras foram centrifugadas a $3.500 \mathrm{rpm}$ por 20 min. Uma alíquota de $500 \mu \mathrm{L}$ do extrato sobrenadante foi retirada e transferida para um vial de $2 \mathrm{~mL}$. $\mathrm{O}$ extrato evaporou-se totalmente sob fluxo de $\mathrm{N}_{2}$ e, posteriormente, retomado em 1 $\mathrm{mL}$ de metanol.

Os extratos foram submetidos à análise cromatográfica, utilizando um cromatógrafo líquido HPLC/UV-Vis modelo Alliance 2695 da marca Waters, equipado com detector UV/Vis modelo 2489 da marca Waters. Na Tabela 3, estão descritas as condições analíticas de operação do HPLC/UV-Vis. A concentração de imidacloprido nas amostras analisadas foi expressa em $\mathrm{mg} \mathrm{L}^{-1}$ de água. Os limites de detecção e quantificação do método foram de 11 e $34 \mu \mathrm{g} \mathrm{L}^{-1}$, respectivamente.

No esterco caprino, também foram analisados resíduos de imidacloprido, utilizando o método QuEChERS (ANASTASSIADES et al., 2003) na etapa de extração.

Após a retirada de todo o efluente dos reatores, colocou-se o esterco caprino em um vidro de relógio e permaneceu à temperatura ambiente durante 48 horas, para remover toda a umidade. A amostra foi homogeneizada e retiradas 5 sub amostras (quintuplicata), cada uma pesando $5 \mathrm{~g}$, que foram colocadas em tubos falcon de $50 \mathrm{~mL}$, quando adicionou-se $1 \mathrm{~mL}$ de água miliQ e $20 \mathrm{~mL}$ de acetonitrila $(\mathrm{MeCN})$ e procedeu agitação vigorosa por $1 \mathrm{~min}$. $\mathrm{Na}$ etapa seguinte, adicionou-se 1 pacote de Q-sep: QuEChERS Extraction Salts, contendo $4 \mathrm{~g}$ $\mathrm{MgSO}_{4}, 1 \mathrm{~g} \mathrm{NaCl}, 1 \mathrm{~g}$ TSCD e 0,5 g DHS, da marca Restek. Repetiu-se, então, a agitação vigorosa por $1 \mathrm{~min}$ e, em seguida, realizou-se a centrifugação a $3500 \mathrm{rpm}$ por $10 \mathrm{~min}$. De cada sub amostra foi retirado $1 \mathrm{~mL}$ do extrato e submetido a uma etapa de clean up, utilizando

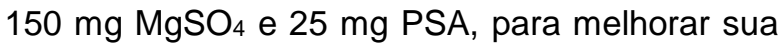


qualidade. Os extratos foram submetidos à análise cromatográfica, utilizando um cromatógrafo líquido HPLC/UV-Vis modelo Alliance 2695 da marca Waters, empregando a mesma condição cromatográfica do efluente.

\subsection{Mapas de Espacialização}

Os mapas de espacialização da temperatura no interior dos reatores foram gerados a partir do interpolador conhecido como Krigagem ordinária, através do software SURFER versão 8.0.

\subsection{Análise Estatística}

Para análise e interpretação dos resultados, empregaram-se as ferramentas da estatística descritiva.

Tabela 3: Parâmetros cromatográficos utilizados na determinação do imidacloprido.

\begin{tabular}{cc}
\hline Coluna & Waters Sunfire ${ }^{\mathrm{TM}} \mathrm{C} 185 \mu \mathrm{m}-4,6 \times 150 \mathrm{~mm}$ \\
Volume de injeção & $10 \mu \mathrm{L}$ \\
Temperatura do forno & $30{ }^{\circ} \mathrm{C}$ \\
Temperatura da amostra & OFF \\
Fase móvel & Isocrático $-50 \%$ Água e $50 \%$ Metanol \\
Fluxo & $0,6 \mathrm{~mL} \mathrm{~min}^{-1}$ \\
Detector & $\mathrm{UV}$ \\
Comprimento de onda & $270 \mathrm{~nm}$ \\
\hline
\end{tabular}

Fonte: Autores.

\section{RESULTADOS E DISCUSSÃO}

A temperatura no interior dos reatores foi medida diariamente durante os 23 dias do experimento. Os reatores com razão efluente/biomassa de 95/5 e 80/20 apresentaram temperatura média de $20,7{ }^{\circ} \mathrm{C}$ e $20,6{ }^{\circ} \mathrm{C}$ respectivamente.

A análise da Figura 3(a) e 3(b) evidenciou que houve uma boa homogeneização da temperatura durante todo 0 experimento, garantindo praticamente a mesma condição de operação a todos os reatores.

Por ser um tratamento aeróbio, no qual o oxigênio é fundamental para a biodegradação, analisou-se o teor de oxigênio dissolvido [Figura 4(a) e 4(b)] nos reatores. Esse parâmetro, nas duas proporções do tratamento (95/5 e 80/20), apresentou uma média equivalente a $7,8 \mathrm{mg} \mathrm{L}^{-1}$ durante os 23 dias do experimento.

O teor de oxigênio dissolvido está de acordo com os trabalhos que utilizam sistemas de tratamento aerado. Jilani e Khan (2014), ao empregarem lodos ativados para degradação do agrotóxico cipermetrina, obtiveram degradação de $88 \%$ em uma faixa de $8-9 \mathrm{mg} \mathrm{L}^{-1}$ de oxigênio dissolvido.

Celis, Elefsiniotis e Singhal (2008) também avaliaram a influência do teor de oxigênio dissolvido em reatores operando sob condições aeróbias e anaeróbias, para biodegradação dos herbicidas isoproturon e 2,4-D. A biodegradação ocorreu mais rapidamente em condições aeróbicas com teor de oxigênio dissolvido superior a $2,0 \mathrm{mg} \mathrm{L}^{-1}$.

\subsection{Biodegradação do imidacloprido}

Na Figura 5, encontra-se o cromatograma do efluente inicial contaminado com imidacloprido na concentração de $2,5 \mathrm{mg} \mathrm{L}^{-1}$. O estudo de recuperação do imidacloprido foi satisfatório tanto no efluente quanto no esterco caprino, obtendose recuperação de $87,2 \%$ e $97,8 \%$ respectivamente, percentuais dentro da faixa aceitável que, segundo Ribani (2004), é de 70 a $120 \%$.

Os resultados das análises cromatográficas no efluente e no esterco demonstraram que houve biodegradação apenas na proporção $80 / 20$. Verificou-se, também, que no tempo zero, aproximadamente $88 \%$ da massa inicial de imidacloprido ficou adsorvida ao esterco caprino, pois ainda não havia iniciado o processo de biodegradação. O que pode ter favorecido o processo de adsorção foi a constante de adsorção ao carbono orgânico - Koc do inseticida, que é moderada, $225 \mathrm{~mL} \mathrm{~g}^{-1}$. 
Figura 3: Mapas de Krigagem para a variável temperatura $\left({ }^{\circ} \mathrm{C}\right)$ no interior dos reatores com proporções 95/5 (a) e 80/20 (b) respectivamente.
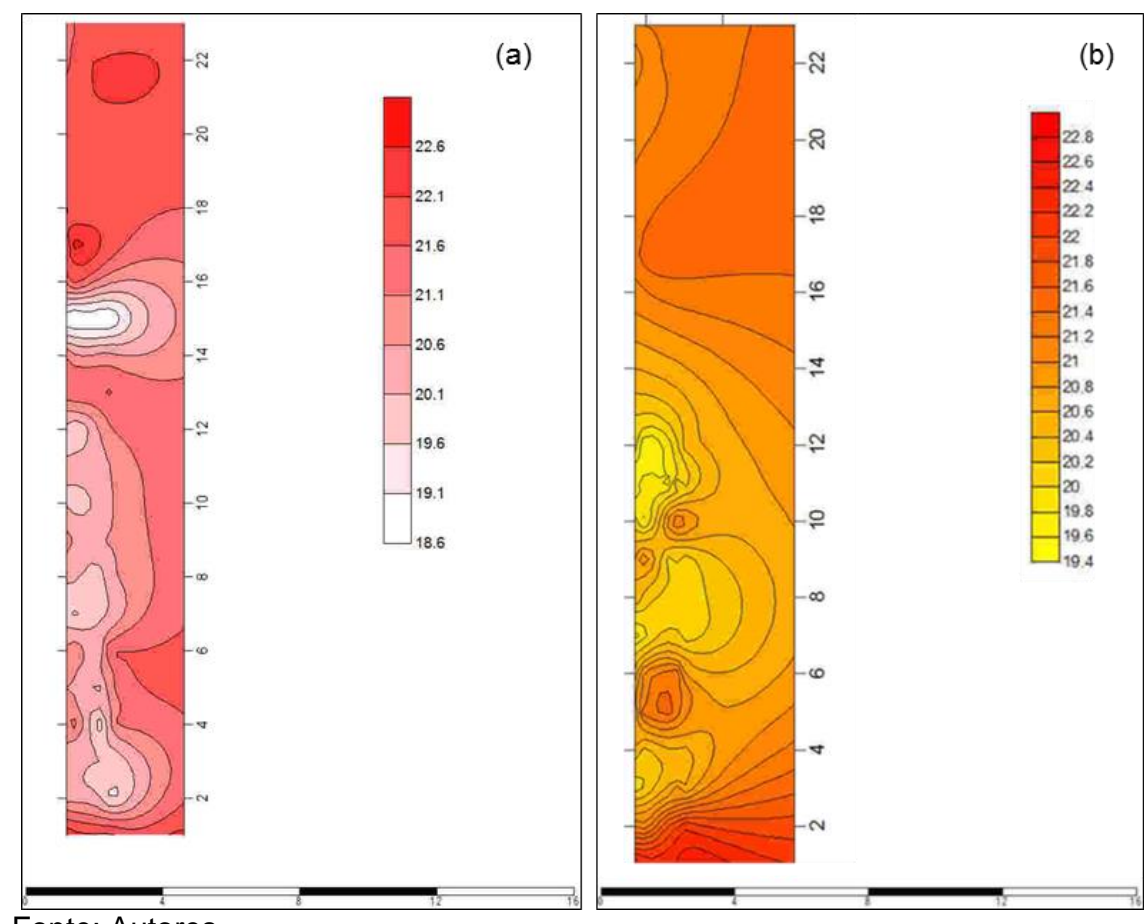

Figura 4: Variação dos teores de oxigênio dissolvido $\left(\mathrm{mg} \mathrm{L}^{-1}\right)$ nos três reatores com proporção efluente/biomassa 95/5 (a) e 80/20 (b) respectivamente.
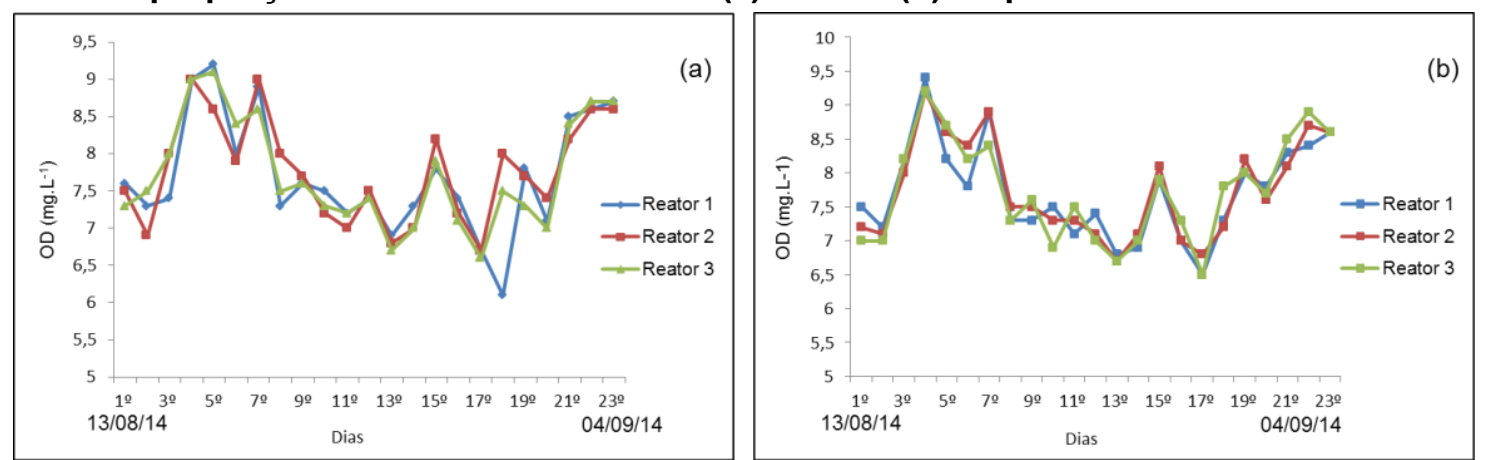

Fonte: Autores.

Figura 5: Cromatograma do efluente inicial contaminado com imidacloprido.

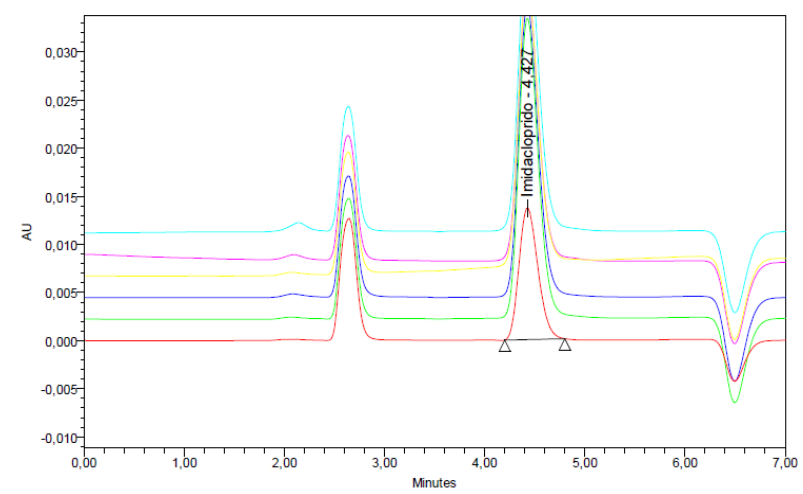

Fonte: Autores. 
Observando a Figura 6, verificou-se que em torno de $40 \%$ e $49,2 \%$ da massa de imidacloprido inicial tinham sido eliminadas do efluente e do esterco caprino respectivamente. $O$ fato de que esse composto não é volátil, pois possui uma baixa pressão de vapor $\left(4,0 \times 10^{-7} \mathrm{mPa}\right)$, sustenta e comprova que o esterco caprino contém microrganismos capazes de degradar 0 imidacloprido, sendo a biodegradação o processo responsável por sua eliminação.

\section{Figura 6: Degradação do imidacloprido no efluente e esterco caprino, na proporção 80/20.}

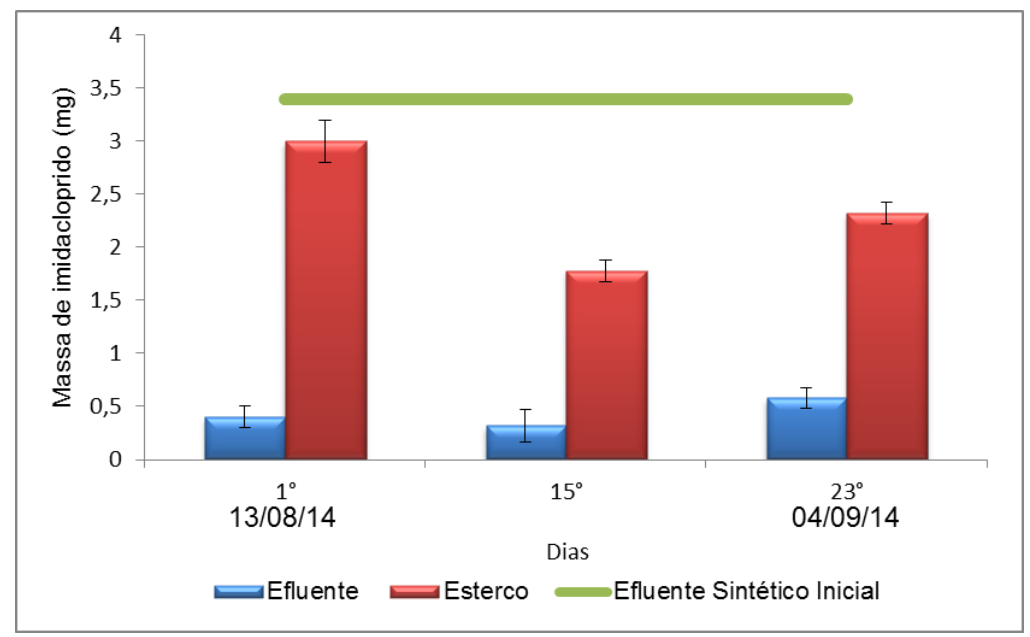

Fonte: Autores.

Resultados semelhantes que comprovam a eficiência do processo de biodegradação também foram obtidos por Delgado-Moreno, Nogales e Romero (2017), em que a utilização de sistemas biológicos (biobeds) foi capaz de remover 100, $80,73,75$ e $50 \%$ da concentração dos agrotóxicos dimetoato, imidacloprido, tebuconazol, diuron e oxifluorfen, respectivamente.

Da mesma forma, Herner, Kucic e Zelic (2017) verificaram taxa máxima (68\%) de biodegradação do imidacloprido, em 7 dias, durante o processo de compostagem em um reator fechado, através da atividade metabólica da suspensão bacteriana de Pseudomonas aeruginosa $\mathrm{FN}$.

$\mathrm{He}$ et al. (2014) também constataram percentuais de biodegradação do imidacloprido bem superiores aos encontrados nesta pesquisa, porém, os autores utilizaram uma comunidade específica modificada do fungo Trichoderma, que foi capaz de degradar $95 \%$ da concentração inicial de imidacloprido. Vale ressaltar que o potencial do fungo Trichoderma para controle biológico e biorremediação foi anteriormente relatado por autores como Colla et al. (2008); Bourgin et al. (2011), Ding, Jacobs e Lavine (2011) e Machado et al. (2012).
Mohammed e Badawy (2017), do mesmo modo, obtiveram biodegradação de $85 \%$ e $96,23 \%$ do imidacloprido ( $25 \mathrm{mg} \mathrm{L}^{-1}$ ), após um período de incubação de 6 e 20 dias respectivamente, através de uma cepa fúngica de YESM3 identificada como Aspergillus terreus.

Em contrapartida, no reator $95 / 5$, mesmo tendo sido constatado a presença de microrganismos, não apresentou biodegradação do imidacloprido. Dois fatores podem ter desfavorecido tal processo: o primeiro deles seria a baixa disponibilidade de nutrientes essenciais ao metabolismo microbiano, como $\mathrm{N}$ e COT (presentes nos 5\% de esterco caprino contido nessa proporção); e o segundo fator interveniente está relacionado com a concentração do inseticida que, provavelmente, tornou-se tóxica para a comunidade microbiana, pois, em virtude da menor quantidade de esterco e conforme figura 8, havia menos UFC nesses reatores se comparados ao 80/20.

Estabelecendo uma correlação para os teores de $\mathrm{N}$ e COT (Tabela 4), nas duas proporções no mesmo tempo de detenção, com 15 dias, verificou-se que a disponibilidade desses nutrientes foi significativamente maior nos reatores com proporção 80/20. Provavelmente, essa oferta maior de nutrientes favoreceu 0 processo de biodegradação. 
Tabela 4: Teores de nitrogênio e carbono orgânico nos reatores.

\begin{tabular}{c|c|c|c|c|c}
\hline \multirow{2}{*}{$\begin{array}{c}\text { Razão } \\
\text { efluente/biomassa }\end{array}$} & \multirow{2}{*}{ Reator } & \multicolumn{3}{|c}{ Parâmetros } \\
\cline { 3 - 6 } & & \multicolumn{2}{|c}{ Nitrogênio $\left(\mathbf{m g ~ L}^{-1}\right)$} & \multicolumn{2}{c}{ COT $\left(\mathbf{m g ~ L}^{-1}\right)$} \\
\cline { 3 - 6 } & $\mathrm{R} 1$ & $31,5 \pm 0,1$ & $154,0 \pm 1,5$ & $1241 \pm 12,0$ & $1506 \pm 17,8$ \\
\hline \multirow{3}{*}{$95 / 5$} & $\mathrm{R} 2$ & $28,0 \pm 0,1$ & $103,2 \pm 1,2$ & $1369 \pm 10,5$ & $1314 \pm 15,0$ \\
\cline { 2 - 6 } & $\mathrm{R} 3$ & $28,0 \pm 0,1$ & $140,0 \pm 1,3$ & $1413 \pm 11,1$ & $1283 \pm 16,7$ \\
\cline { 2 - 6 } & $\mathrm{R} 1$ & $166,2 \pm 0,5$ & $813,2 \pm 2,5$ & $6209 \pm 22,5$ & $4510 \pm 14,3$ \\
\cline { 2 - 6 } & $\mathrm{R} 2$ & $161,0 \pm 0,3$ & $824,3 \pm 2,1$ & $6132 \pm 20,2$ & $5026 \pm 15,8$ \\
\cline { 2 - 6 } $80 / 20$ & $\mathrm{R} 3$ & $164,0 \pm 0,2$ & $775,3 \pm 1,6$ & $5955 \pm 18,3$ & $5358 \pm 13,2$ \\
\hline
\end{tabular}

Fonte: Autores.

Omirou et al. (2012) afirmam que o aumento no teor de nutrientes no biomix (uma mistura de solo agrícola, palha e turfa) aumentou a atividade microbiana e a biodegradação de agrotóxicos, corroborando com os resultados encontrados nesta pesquisa. Affam et al. (2014) também relatam que os nutrientes orgânicos são considerados como fatores necessários ao crescimento dos microrganismos, pois atuam como precursores de material celular orgânico.

Uma redução na taxa de biodegradação, associada à deficiência de nutrientes e/ou acúmulo de produtos de degradação dos agrotóxicos foram, também, constatados por Affam et al. (2014) ao combinarem UV fenton com um tratamento biológico, para degradar efluentes contaminados com agrotóxicos.

Quando o efluente não dispõe de nutrientes, estes precisam ser adicionados para que ocorra 0 tratamento biológico (METCALF; EDDY, 2002). O nível de degradação de compostos xenobióticos depende do tipo de substrato a ser degradado e da diversidade bacteriana (KONG et al., 2013). Segundo Kumar e Philip (2006), a adição de uma fonte de carbono aumenta o potencial de biodegradação de compostos xenobióticos. Por conta disso, a biodegradação na proporção 95/5 não foi eficiente.

Castillo e Torstensson (2007) também encontraram uma correlação positiva entre o teor de nutrientes e a capacidade de degradação em biomix à base de turfa. Com relação ao efeito tóxico que o composto original e seus metabólitos podem causar à comunidade microbiana, Stasinakis et al. (2009) constataram que elevadas concentrações de agrotóxicos no reator pode impedir 0 crescimento de microrganismos degradadores. Em experimentos empregando tratamento biológico, o potencial de biodegradação de xenobióticos é afetado pela concentração inicial do respectivo agrotóxico (GRADY, 1985; KAWAl et al., 1998).

Outro fator que pode ter desfavorecido o processo de biodegradação, em ambas as proporções aqui estudadas, foi a aclimatação da comunidade microbiana. Neste estudo, não se fez a aclimatação da biomassa, pois o objetivo do trabalho foi propor uma alternativa de tratamento simples, condizente com a realidade dos produtores de uva do Vale do São Francisco.

Estudos anteriores constataram que a aclimatação da biomassa, também conhecida como start up, potencializa a biodegradação de agrotóxicos (MANGAT; ELEFSINIOTIS, 1999; STASINAKIS et al., 2005). Porém, apesar de não se ter realizado o start up da comunidade microbiana nesta pesquisa, constatou-se uma eficiência de degradação de $40 \%$ no efluente sintético e $59 \%$ no esterco caprino.

Segundo Celis, Elefsiniotis e Singhal (2008), - start up da comunidade microbiana é fundamental para um melhor desempenho da biodegradação. Os trabalhos empregando biorreatores para degradar agrotóxicos, geralmente, incorporam essa prática, para permitir o acúmulo de biomassa, minimizar quaisquer problemas devido a efeitos tóxicos e melhorar o funcionamento e a estabilidade dos biorreatores (TOMEI; ANNESINI; BUSSOLETTI, 2004; HU et al., 2005; CELIS; ELEFSINIOTIS; SINGHAL, 2008).

Mesmo não se tendo realizado a fase de start up da comunidade microbiana no interior dos reatores, ficou claramente estabelecido que o processo de biodegradação foi mais acelerado no esterco caprino se comparado ao efluente sintético. 
Uma abordagem semelhante foi seguida no estudo de Znad, Kasahara e Kawase (2006), em que os autores verificaram que a biodegradação do herbicida S-ethyl dipropylthiocarbamate (EPTC) foi de $35 \%$ nos biorreatores preenchidos com lodos ativados livremente suspensos, enquanto que nos preenchidos com uma camada imobilizada, operando sob as mesmas condições, a taxa de biodegradação foi de $72 \%$.

Fazendo uma analogia aos tratamentos que utilizam biobeds para degradar efluentes contaminados com agrotóxicos, autores como Fogg et al. (2003), Omirou et al. (2012) e Karanasios, Tsiropoulos e Karpouzas (2013), também, verificaram que a biodegradação dos agrotóxicos foi substancialmente mais rápida no biomix do que na camada superficial do solo.

Estabelecendo uma correlação entre biodegradação e temperatura, verificou-se que, no décimo quinto dia de tratamento na proporção $80 / 20$, a temperatura média foi de $20,6{ }^{\circ} \mathrm{C}$, e constatou-se uma taxa de biodegradação do imidacloprido no efluente sintético de, aproximadamente, $40 \%$. Resultados semelhantes foram encontrados por Phugare et al. (2013), os quais relatam que, nessa mesma faixa de temperatura $\left(20{ }^{\circ} \mathrm{C}\right)$, a biodegradação do imidacloprido foi de $30,4 \%$ em um período de sete dias.

Esses mesmos autores analisaram a degradação do imidacloprido por bactérias isoladas de Klebsiella pneumoniaestrain $\mathrm{BCH} 1 \mathrm{~K}$ e constataram que a temperatura influenciou, significativamente, a biodegradação. Os autores verificaram que as temperaturas de 10 e $20{ }^{\circ} \mathrm{C}$ apresentaram simultaneamente os menores percentuais de degradação, cerca de 24,1 e 30,4 , enquanto que em temperaturas elevadas de $40 \mathrm{e}$ $50{ }^{\circ} \mathrm{C}$ observou-se $62,3 \%$ e $38,8 \%$ de degradação, respectivamente.

A otimização de parâmetros ambientais, como temperatura, é fundamental para o sucesso da biodegradação (PHUGARE et al., 2013). Estudos de otimização foram anteriormente desenvolvidos por Deshpande et al. (2004), para biodegradação do inseticida organofosforado dimethoate, empregando Brevundimonas sp. MCM B-427.

\subsection{Carbono orgânico total - COT}

Buscando avaliar a taxa de mineralização durante a biodegradação, realizou-se a análise de carbono orgânico - COT. Neste estudo, a análise do COT também foi usada como indicador para avaliar a degradação do imidacloprido. A Figura 7 mostra que durante quinze dias, período no qual ocorreu a maior taxa de biodegradação, houve redução do teor de COT nos reatores com proporção 80/20.

A análise do COT também foi usada como indicador para avaliar a mineralização. Nos resultados apresentados na Tabela 5 , pode-se observar que, para a proporção $80 / 20$, houve uma taxa média de mineralização de $18,5 \%$, no período de quinze dias, e $13,0 \%$ no período de 23 dias; já as taxas de degradação do imidacloprido foram de $38,2 \%$ e $24,9 \%$, respectivamente.

\section{Figura 7: Variação dos teores de COT $\left(\mathrm{mg} \mathrm{L}^{-1}\right)$ nos três reatores com proporção} efluente/ biomassa: 80/20.

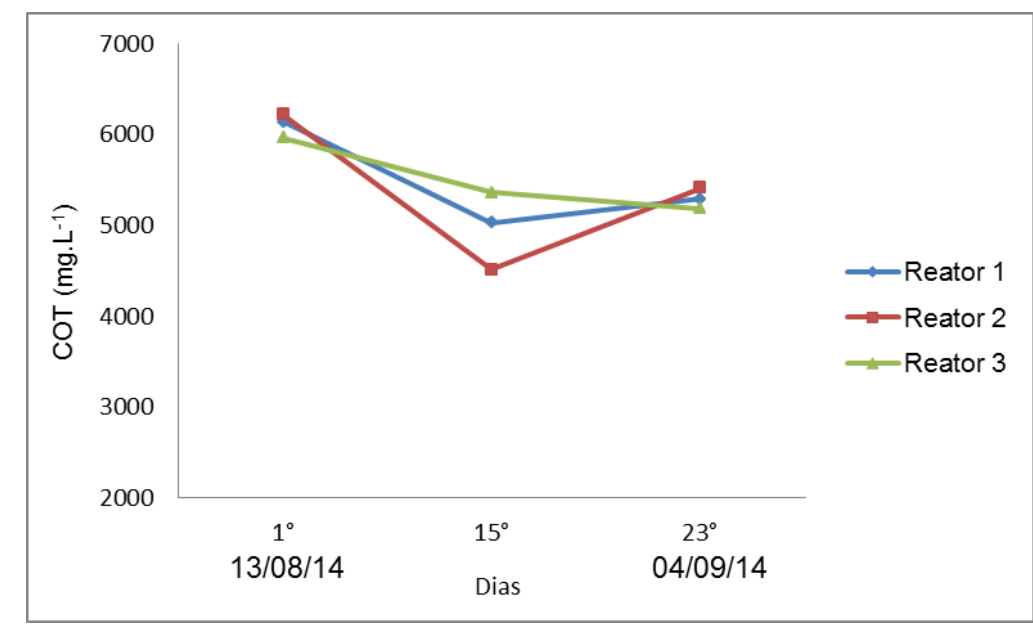

Fonte: Autores. 


\section{Tabela 5: Comparação entre a degradação e a mineralização do COT nos diferentes tempos de detenção para a razão efluente/biomassa 80/20.}

\begin{tabular}{ccc} 
Tempo de detenção & T15 & T23 \\
\hline Mineralização (\%) & 18,5 & 13 \\
\hline Degradação (\%) & 38,2 & 24,9 \\
\hline
\end{tabular}

Patil, Patil e Gogate (2014) relataram resultados semelhantes, com mineralização de $15 \%$ do carbono orgânico, empregando ultra-som e aditivos químicos para degradar efluentes contaminados com imidacloprido.

Os resultados mostrados na Tabela 5 evidenciam que o COT foi influenciado pela ação da biodegradação e que, neste estudo, a biodegradação foi mais rápida que a mineralização do COT, o que corrobora com a literatura, pois, segundo Zabar et al. (2012), a taxa de mineralização é usualmente mais lenta que a taxa de degradação de agrotóxicos. Os mesmos autores realizaram um estudo da degradação fotocatalítica com $\mathrm{TiO}_{2}$, em que a mineralização de COT do imidacloprido foi $19,1 \%$ e a degradação $98,8 \%$.

O estudo desenvolvido por Philippidis et al. (2009) também evidenciou que a mineralização foi mais lenta que a fotodegradação. No referido estudo, com 18 horas de oxidação fotocatalítica empregando $\mathrm{TiO}_{2}$ para degradar imidacloprido, obteve-se mineralização do COT de $66 \%$ e degradação quase completa do agrotóxico.

\subsection{Microbiológica}

Com relação à análise microbiológica [Figura 8(a) e 8(b)] nos 3 meios de cultura, foram encontrados entre $10^{4}$ a $10^{7}$ unidades formadoras de colônias - UFC nas amostras do efluente no decorrer de todo o tratamento, em ambas as proporções (95/5 e 80/20) estudadas. Vale ressaltar que, nos reatores com proporção 80/20, a quantidade de UFC foi superior $\left(10^{3}\right)$ se comparada aos reatores com proporção 95/5, o que pode ter favorecido 0 processo de biodegradação nos reatores com proporção $80 / 20$, visto que nesse tratamento continha uma maior quantidade de esterco caprino.

A análise microbiológica foi extremamente importante, pois 0 crescimento de microrganismos no meio de cultura Pobre+P.A. (pobre em nutrientes, com adição de $2 \mathrm{~g} \mathrm{~L}^{-1}$ de imidacloprido) comprovou que o esterco caprino possui microrganismos com potencial de biodegradação de agrotóxicos (Figura 9), haja vista que, neste meio de cultura, a principal fonte de nutrientes é o próprio imidacloprido.

Resultados semelhantes de biodegradação desse mesmo composto também foram constatados por He et al. (2014), Sharma, Singh e Gupta (2014), Mohammed e Badawy (2017), Delgado-Moreno, Nogales e Romero (2017) e Herner, Kucic e Zelic (2017).

Anhalt, Moorman e Koskinen (2007) estudaram o potencial da bactéria de Leifsonia sp. para degradar o imidacloprido. Os autores relataram que essa bactéria foi capaz de degradar o imidacloprido (Ácido 6-cloronicotínico) dentro de três semanas.

De acordo com Silva, Melo e Fay (2004), os resíduos de agrotóxicos podem ser mineralizados por uma comunidade microbiana, e a taxa de crescimento microbiano está diretamente relacionada à concentração do agrotóxico e à diversidade do substrato. Segundo Johnsen et al. (2001), alguns microrganismos são capazes de utilizar o próprio agrotóxico como fonte de energia e nutrientes.

Resultados semelhantes em que os microrganismos utilizaram o próprio agrotóxico como única fonte de enxofre e carbono para o crescimento microbiano foram também relatados por autores como Kwon et al. (2005), Hussain et al. (2007) e Castillo, Casas e Romero (2011).

Wolski, Murialdo e Gonzalez (2006) relataram que um isolado de Pseudomonas sp. foi capaz de utilizar o pentaclorofenol (PCP) como fonte de carbono e nitrogênio em meio mínimo para biodegradação desse composto. Kasemodel, Porto e Nitschke (2014) também constataram microrganismos capazes de utilizar os agrotóxicos dieldrin e PCP como fonte de carbono no processo de biodegradação. 
Figura 8: Contagem de microrganismos (UFC mL-1) nos três reatores com proporção efluente/ biomassa 95/5 (a) e 80/20 (b) respectivamente.
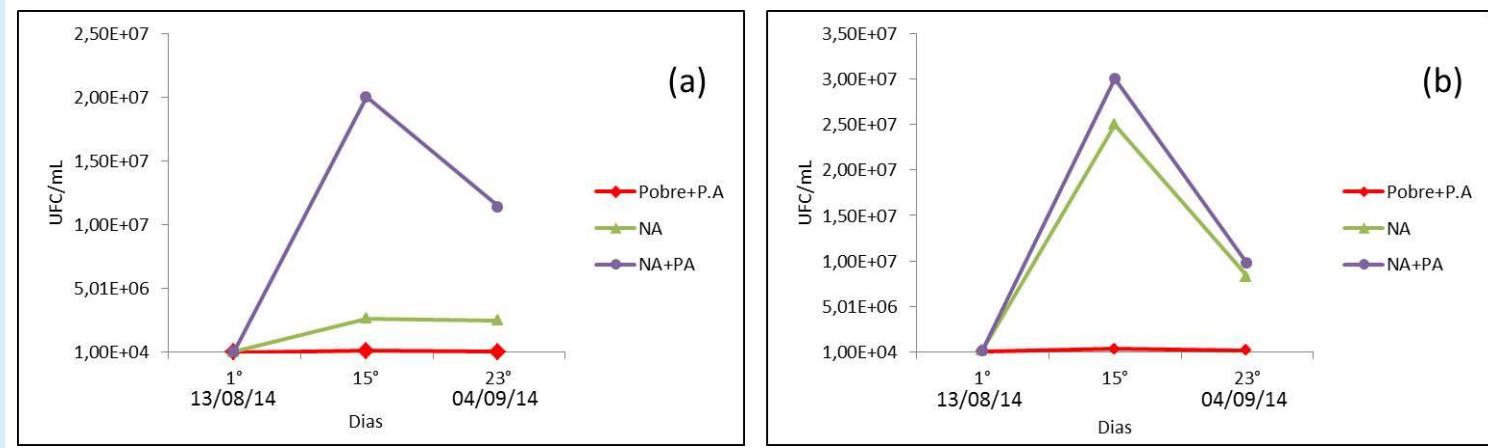

Fonte: Autores.

Figura 9: Placas com meio de cultura Pobre+P.A.

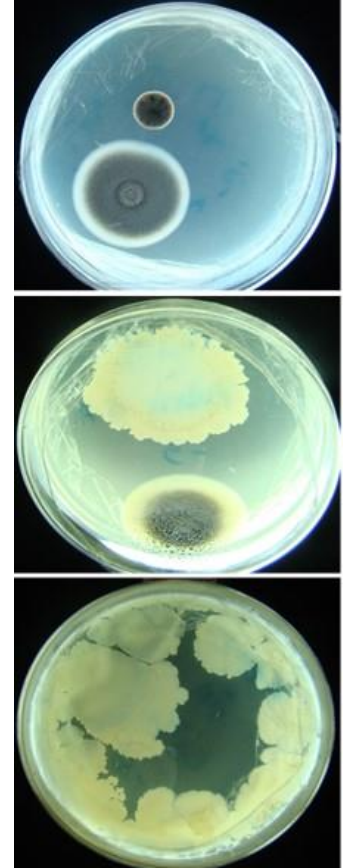

Fonte: Autores.

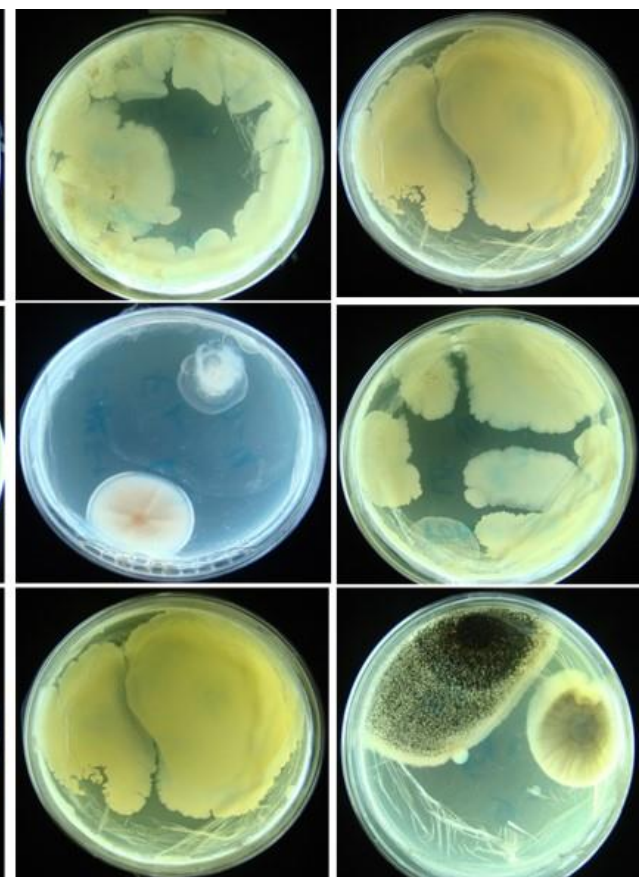

\section{CONCLUSÃO}

O esterco caprino contém microrganismos com potencial para biodegradação do imidacloprido no efluente. A melhor proporção estudada foi a $80 / 20$ (efluente/biomassa), sendo capaz de biodegradar, aproximadamente, $40 \%$ da concentração inicial de imidacloprido no efluente sintético, em um período de quinze dias. Como esse percentual de biodegradação precisa ser melhorado, é fundamental estudar alternativas para aumentar a eficiência do tratamento.

Fazendo uma comparação nas taxas de biodegradação, constatou-se que o processo foi mais acelerado no esterco caprino, com aproximadamente $50 \%$. Isso pode estar relacionado, principalmente, ao acúmulo de microrganismos na camada imobilizada de esterco, onde fica retida a maior quantidade do agrotóxico.

\section{AGRADECIMENTOS}

À Embrapa Semiárido, Universidade Federal do Vale do São Francisco, Universidade Federal de Campina Grande, Capes e Facepe, por apoiarem, financiarem e fomentarem esta pesquisa. 


\section{REFERÊNCIAS}

ABRASCO - ASSOCIAÇÃO BRASILEIRA DE SAÚDE COLETIVA. Um alerta sobre os impactos dos agrotóxicos na saúde. Parte 2 - Agrotóxicos, Saúde, Ambiente e Sustentabilidade (DOSSIÊ). AUGUSTO, L. G. S.; CARNEIRO, F. F.; PIGNATI, W.; RIGOTTO, R. M.; FRIEDRICH, K.; FARIA, N. M. X.; BÚRIGO, A. C.; FREITAS, V. M. T.; GUIDUCCI FILHO, E.. Rio de Janeiro: ABRASCO, 2012.

AFFAM, A. C.; CHAUDHURI, M.; KUTTY, S. R. M.; MUDA, K. Fenton and sequencing batch reactor treatment of chlorpyrifos, cypermethrin and chlorothalonil pesticide wastewater. International Biodeterioration \& Biodegradation, v. 93, p. 195-201, 2014.

ANASTASSIADES, M.; LEHOTAY, S. J.; STAJNBAHER, D.; SCHENCK, F. J. Fast and easy multiresidue method employing acetonitrile extraction/partitioning and "dispersive solid-phase extraction" for the determination of pesticide residues in produce. Journal of the Association of Official Analytical Chesmists International, v. 86, p. 412-431, 2003.

ANHALT, J. C.; MOORMAN, T. B.; KOSKINEN, W. C. Biodegradation of imidacloprid by an isolated soil microorganism. Journal of Environmental Science and Health, v. 42, n. 8, p. 509-514, 2007.

ANVISA - Agência Nacional de Vigilância Sanitária. Consulta Pública oㅡ 01, de 29 de janeiro de 2007. Diário Oficial da União de 31/01/2007. Disponível em: <http://www4.anvisa.gov.br/base/visadoc/CP/CP[17410 -1-0].PDF >. Acesso em: 05 fev. 2018.

APHA - American Public Health Association. Standard Methods for the Examination of Water and Wastewater, 22th edition. Washington: American Water Works Association - Water Environment Federation, 2012.

BORTOLUZZI, E. C.; RHEINHEIMER, D. S.; GONÇALVES, C. S.; PELLEGRINI, J. B. R.; ZANELLA, R.; COPETTI, A. C. C. Contaminação de águas superficiais por agrotóxicos em função do uso do solo numa microbacia hidrográfica de Agudo, RS. Revista Brasileira de Engenharia Agrícola e Ambiental, v. 10, n. 4, p. 881-887, 2006.

BOURGIN, M.; VIOLLEAU, F.; DEBRAUWER, L.; ALBET, J. Ozonation of imidacloprid in aqueous solutions: reaction monitoring and identification of degradation products. Journal of Hazardous Materials, v. 190, n. 1-3, p. 60-68, 2011.
CARDEAL, Z. L.; SOUZA, A. G.; AMORIM, L. C. A. Analytical methods for performing pesticide degradation studies in environmental sample. In: Pesticides formulations, effects, fate. New York: In Tech Publishers, 2011. p. 595-618.

CARNEIRO, F.F. (Org.). Dossiê ABRASCO: um alerta sobre os impactos dos agrotóxicos na saúde. EPSJV/Expressão Popular, 2015.

CASTILLO, J. M.; CASAS, J.; ROMERO, E. Isolation of an endosulfan-degrading bacterium from a coffee farm soil: persistence and inhibitory effect on its biological functions. Science of the Total Environment, v. 412413, p. 20-27, 2011.

CASTILLO, M. P.; TORSTENSSON, L. Effect of biobed composition, moisture and temperature on the degradation of pesticides. Journal of Agricultural \& Food Chemistry, v. 55, p. 5725-5733, 2007.

CELIS, E.; ELEFSINIOTIS, P.; SINGHAL, N. Biodegradation of agricultural herbicides in sequencing batch reactors under aerobic or anaerobic conditions. Water Research, v. 42, p. 3218-3224, 2008.

COLLA, L. M.; PRIMAZ, A. L.; LIMA, M.; BERTOLIN, T. E.; COSTA, J. A. V. Isolamento e seleção de fungos para birremediação a partir de solos contaminados com herbicidas triazínicos. Revista Ciência e Agrotecnologia, v. 32, n. 3, p. 809-813, 2008.

DELGADO-MORENO, L.; NOGALES, R.; ROMERO, E. Biodegradation of high doses of commercial pesticide products in pilot-scale biobeds using olive-oil agroindustry wastes. Journal of Environmental Management, v. 204, p. 160-169, 2017.

DESHPANDE, N. M.; SARNAIK, S. S.; PARANJPE, S. A.; KANEKAR, P. P. Optimization of dimethoate degradation by Brevundimonas sp. MCM B-427 using factorial design: studies on interactive effects of environmental factors. World Journal of Microbiology \& Biotechnology, v. 20, p. 455-462, 2004.

DIEZ, M. C. Biological aspects involved in the degradation of organic pollutants. Journal of Soil Science and Plant Nutrition, v. 10, n. 3, p. 244-267, 2010.

DING, T.; JACOBS, D.; LAVINE, B. K. Liquid chromatography-mass spectrometry identification of imidacloprid photolysis products. Microchemical Journal, v. 99, n. 2, p. 535-541, 2011.

FERNANDES NETO, M. L.; SARCINELLI, P. N. Agrotóxicos em água para consumo humano: uma abordagem de avaliação de risco e contribuição ao processo de atualização da legislação brasileira. 
Revista Engenharia Sanitária Ambiental, v. 14, n. 1, p. 69-78, 2009.

FERREIRA, M. J. M.; VIANA JÚNIOR, M. M.; PONTES, A. G. V.; RIGOTTO, R. M.; GADELHA, D. Gestão e uso dos recursos hídricos e a expansão do agronegócio: água para quê e para quem? Ciência \& Saúde Coletiva, v. 21, p. 743-752, 2016.

FOGG, P.; BOXALL, A. B. A.; WALKER, A.; JUKES, A. A. Pesticide degradation in a "biobed" composting substrate. Pest Management Science, v. 59, p. 527537, 2003.

GOGATE, P. R.; PANDIT, A. B. A review of imperative technologies for wastewater treatment II: hybrid methods. Advances in Environmental Research, v. 8, p. 553-597, 2004.

GRADY JR. C. P. L. Biodegradation: its measurement and microbiological basis. Biotechnology and Bioengineering, v. 27, p. 660-674, 1985.

HATTAB, M. T; GHALY, A. E. Disposal and treatment methods for pesticide containing wastewaters: critical review and comparative analysis. Journal of Environmental Protection, v. 3, n. 5, p. 431-453, 2012.

HE, X.; WUBIE, A. J.; DIAO, Q.; LI, W.; XUE, F.; GUO, Z.; ZHOU, T.; XU, S. Biodegradation of neonicotinoid insecticide, imidacloprid by restriction enzyme mediated integration (REMI) generated Trichoderma mutants. Chemosphere, v. 112, p. 526-530, 2014.

HERNER, Z.; KUCIC, D.; ZELIC, B. Biodegradation of imidacloprid by composting process. Chemical Papers, v. 71, n. 1 , p. 13-20, 2017.

HERRERO-HERNÁNDEZ, E. H.; ANDRADES, M. S.; MARTÍN, A. A.; JUAN, E. P.; CRUZ, M. S. R.; MARTÍN, M. J. S. Occurrence of pesticides and some of their degradation products in waters in a Spanish wine region. Journal of Hydrology, v. 486, p. 234-245, 2013.

HU, Z.; FERRAINA, R. A.; ERICSON, J. F.; MACKAY, A. A.; SMETS, B. F. Biomass characteristics in three sequencing batch reactors treating a wastewater containing synthetic organic chemicals. Water Research, v. 39, n. 4, p. 710-720, 2005.

HUSSAIN, S.; ARSHAD, M.; SALEEM, M.; KHALID, A. Biodegradation of $\alpha$ and $\beta$ - endosulfan by soil bacteria. Biodegradation, v. 18, n. 6, p. 731-740, 2007.

JILANI, S.; KHAN, M. A. Treatment of toxic organics in industrial wastewater using activated sludge process.
International Journal of Environmental Research, v. 8, n. 3, p. 719-726, 2014.

JOHNSEN, K.; JACOBSEN, C. S.; TORSVIK, V.; SORENSEN, J. Pesticide effects on bacterial diversity in agricultural soils - a review. Biology and Fertility of Soils, v. 33, p. 443-453, 2001.

KARANASIOS, E. C.; TSIROPOULOS, N. G.; KARPOUZAS, D. G. Quantitative and qualitative differences in the metabolism of pesticides in biobed substrates and soil. Chemosphere, v. 93, p. 20-28, 2013.

KASEMODEL, M. C.; PORTO, A. L. M.; NITSCHKE, M. Biodegradação bacteriana de compostos organoclorados. Revista Química Nova, v. XY, n. 00, p. 1-6, 2014.

KAWAI, S.; KUROKAWA, Y.; HARINO, H.; FUKUSHIMA, M. Degradation of tributyltin by a bacterial strain isolated from polluted river water. Environmental Pollution, v. 102, p. 259-263, 1998.

KONG, L.; ZHU, S.; ZHU, L.; XIE, H.; SU, K.; YAN, T.; WANG, J.; WANG, J.; WANG, F.; SUN, F. Biodegradation of organochlorine pesticide endosulfan by bacterial strain Alcaligenes faecalisJBW4. Journal of Environmental Sciences, v. 25, n. 11, p. 22572264, 2013.

KUMAR, M.; PHILIP, L.; Bioremediation of endosulfan contaminated soil and water - optimization of operating conditions in laboratory scale reactors. Journal of Hazardous Materials, v.136, n. 2, p. 354-364, 2006.

KWON, G.S.; SOHN, H. Y.; SHIN, K. S.; KIM, E.; SEO, $B$. I. Biodegradation of the organochlorine insecticide, endosulfan, and the toxic metabolite, endosulfan sulfate, by Klebsiella oxytoca KE-8. Applied Microbiology and Biotechnology, v. 67, n. 6, p. 845850, 2005.

MACHADO, D. F. M.; PARZIANELLO, F. R.; SILVA, A. C. F.; ANTONIOLLI, Z. I. Trichoderma no Brasil: o fungo e o bioagente. Revista de Ciências Agrárias, v. 35, n. 26, p. 274-288, 2012.

MANGAT, S. S.; ELEFSINIOTIS, P. Biodegradation of the herbicide 2,4-dichlorophenoxyacetic acid (2,4-D) in sequencing batch reactors. Water Research, v. 33, n. 3, p. 861-867, 1999.

MARCHESAN, E.; SARTORI, G. M. S.; AVILA, L. A.; MACHADO, S. L. O.; ZANELLA, R.; PRIMEL, E. G.; MACEDO, V. R. M.; MARCHEZAN, M. G. Resíduos de agrotóxicos na água de rios da Depressão Central do Estado do Rio Grande do Sul, Brasil. Revista Ciência Rural, v. 40, n. 5, p. 1053-1059, 2010. 
METCALF AND EDDY. Wastewater Engineering Treatment Disposal Reuse. 4를 ed. Washington: Tata McGraw-Hill, 2002.

MOHAMMED, Y. M. M.; BADAWY, M. E. I. Biodegradation of imidacloprid in liquid media by an isolated wastewater fungus Aspergillus terreus YESM3. Journal of Environmental Science and Health, Part B, v. 52, n. 10, p. 752-761, 2017.

MOREIRA, J. C.; PERES, F.; SIMÕES, A. C.; PIGNATI, W. A.; DORES, E. C.; VIEIRA, S. N.; STRÜSSMANN, C.; MOTT, T. Contaminação de águas superficiais e de chuva por agrotóxicos em uma região do estado do Mato Grosso. Revista Ciência \& Saúde Coletiva, v. 17, n. 6, p. 1557-1568, 2012.

OMIROU, M.; DALIAS, P.; COSTA, C.; PAPASTEFANOU, C.; DADOS, A.; EHALIOTIS, C.; KARPOUZAS, D.G. Exploring the potential of biobed's for the depuration of pesticide-contaminated wastewaters from the citrus production chain: laboratory, column and field studies. Environmental Pollution, v.166, p. 31-39, 2012.

PATIL, A. L.; PATIL, P. N.; GOGATE, P. R. Degradation of imidacloprid containing wastewaters using ultrasound based treatment strategies. Ultrasonics Sonochemistry, v. 21, p. 1350-4177, 2014.

PHILIPPIDIS, N.; SOTIROPOULOS, S.; EFSTATHIOU, A.; POULIOS, I. Photoelectrocatalytic degradation of the insecticide imidacloprid using $\mathrm{TiO}_{2} / \mathrm{Ti}$ electrodes. Journal of Photochemistry and Photobiology A: Chemistry, v. 204, p. 129-136, 2009.

PHUGARE, S. S.; KALYANI, D. C.; GAIKWAD, Y. B; JADHAV, J. P. Microbial degradation of imidacloprid and toxicological analysis of its biodegradation metabolites in silkworm (Bombyx mori). Chemical Engineering Journal, v. 230, p. 27-35, 2013.

REILLY, T. J.; SMALLING, K. L.; ORLANDO, J. L.; KUIVILA, K. M. Occurrence of boscalid and other selected fungicides in surface water and groundwater in three targeted use areas in the United States. Chemosphere, v. 89, p. 228-234, 2012.

RIBANI, M. Validação em métodos cromatográficos e eletroforéticos. Revista Química Nova, v. 27, p. 771780, 2004.

RIBAS, P. P.; MATSUMURA, A. T. S. A Química dos agrotóxicos: impactos sobre a saúde e o meio ambiente. Revista Liberato, v. 10, n. 14, p. 149-158, 2009.
SEGURA, C.; ZAROR, C.; MANSILLA, H. D.; MONDACA, M. A. Imidacloprid oxidation by photoFenton reaction. Journal of Hazardous Materials, v. 150, n. 3, p. 679-686, 2008.

SHARMA, S.; SINGH, B.; GUPTA, V. K. Biodegradation of imidacloprid by consortium of two soil isolated Bacillus sp. Bulletin of Environmental Contamination and Toxicology, v. 93, n. 5, p. 637-642, 2014.

SILVA, C. M. M .S.; MELO, I. F.; FAY, E. F. Biotransformação de agrotóxicos e biorremediação. In: SILVA, C. M. M. S. e FAY, E. F. Agrotóxicos e ambiente. Brasília: Embrapa Informação Tecnológica, 2004.

SILVA, D. R. O.; AVILA, L. A.; AGOSTINETTO, D.; BUNDT, A. C.; PRIMEL, A. G.; CALDAS, S. S. Ocorrência de agrotóxicos em águas subterrâneas de áreas adjacentes a lavouras de arroz irrigado. Revista Química Nova, v. 34, n. 5, p. 748-752, 2011.

SOARES, D. F.; FARIA, A. M.; ROSA, A. H. Análise de risco de contaminação de águas subterrâneas por resíduos de agrotóxicos no município de Campo Novo do Parecis (MT), Brasil. Engenharia Sanitária e Ambiental, v. 22, n. 2, 2017.

STASINAKIS, A. S.; KOTSIFA, S.; GATIDOU, G.; MAMAIS, D. Diuron biodegradation in activated sludge batch reactors under aerobic and anoxic conditions. Water Research, v. 43, p. 1471-1479, 2009.

THOMAIDIS, N. S.; NIKOLAOU, A.; KANTIFES, A. Aerobic biodegradation of organotin compounds in activated sludge batch reactors. Environmental Pollution, v. 134, n. 3, p. 431-438, 2005.

TISLER, T.; JEMEC, A.; MOZETIC, B.; TREBSE, P. Hazard identification of imidacloprido to aquatic environment. Chemosphere, v. 76, n. 7, p. 907-914, 2009 .

TOMEI, M. C.; ANNESINI, M. C.; BUSSOLETTI, S. 4Nitrophenol biodegradation in a sequencing batch reactor: kinetic study and effect of filling time. Water Research, v. 38, n. 2, p. 375-384, 2004.

WOLSKI, E. A.; MURIALDO, S. E.; GONZALEZ, J. F. Effect of $\mathrm{pH}$ and inoculum size on pentachlorophenol degradation by Pseudomonas sp. Water SA, v. 32, n. 1, p. 1-5, 2006.

ZABAR, R.; KOMEL, T.; FABJAN, J.; KRALJ, M. B.; TREBŠE, $P$. Photocatalytic degradation with immobilized $\mathrm{TiO}_{2}$ of three selected neonicotinoid insecticides: Imidacloprid, thiamethoxam and clothianidin. Chemosphere, v. 89, p. 293-301, 2012. 
ZNAD, H.; KASAHARA, N.; KAWASE, Y. Biological decomposition of herbicides (EPTC) by activated sludge in a slurry bioreactor. Process Biochemistry, v. 41 ,

p.

1124-1128, 